\title{
AUTISMO E A EDUCAÇÃO: CIÊNCIA ABA (ANÁLISE DO COMPORTAMENTO APLICADA) COMO PROPOSTA DE INTERVENÇÃO NA EDUCAÇÃO INFANTIL
}

\author{
Daniela dos Santos Ferreira Oliveira ${ }^{1}$ \\ Anderson Douglas Pereira Rodrigues da Silva ${ }^{2}$
}

RESUMO: O presente artigo tem como foco o autismo e a educação-intervenção com a ciência ABA (Applied Behavior Analysis). Incluir é a capacidade de compreender reconhecendo o outro com especificidade e limitações. Este artigo tem como objetivo geral de identificar as principais contribuições para o desenvolvimento cognitivo do aluno autista a partir da intervenção feita através da análise do comportamento aplicada-ABA. Em seu desenvolvimento caracteriza-se em uma pesquisa de abordagem qualitativa, tendo como objeto de estudo exploratório onde tem o intuito de explorar a revisão bibliográfica sobre o tem autismo e educação, em busca de descrever o método ABA como proposta de intervenção na educação infantil. Através da análise bibliográfica de forma exploratória de investigar teoricamente e descrever sobre o método ABA como proposta de intervenção na educação infantil constatou-se que a educação inclusiva, a escola precisa estar preparada para enfrentar os desafios e necessidades de oferecer uma educação com qualidade para todos os seus alunos. Torna-se fundamental que a educação com qualidade considere que, cada aluno numa escola, demonstra características próprias no ritmo de aprendizagem, na diversidade de interesses e no conjunto de valores e informações que os tornam únicos e especiais.

Palavras-chave: Education. ABA. Early Childhood Education.

ABSTRACT: This article focuses on autism and education-intervention using the ABA (Applied Behavior Analysis) method. Including is the ability to understand while recognizing the other with specificity and limitations. This article has the general objective of identifying the main contributions to the cognitive development of the autistic student from the intervention made through the analysis of applied behavior-ABA. In its development it is characterized in a research of qualitative approach, having as object of exploratory study where it has the intention of exploring

\footnotetext{
I Psicopedagoga e neuro psicopedagoga- Faveni. E-mail: suzanemicalalegria@gmail.com

2 Doutor em Educação Matemática e Tecnológica Programa de Pós-Graduação em Educação Matemática e Tecnológica (EDUMATEC/UFPE)
} 
the bibliographic review on the subject of autism and education, in search of describing the ABA method as an intervention proposal in early childhood education. Through bibliographic analysis in an exploratory way of investigating theoretically and describing the ABA method as a proposal for intervention in early childhood education, it was found that inclusive education, the school needs to be prepared to face the challenges and needs of offering quality education for all your students. It is essential that quality education considers that, each student in a school, demonstrates its own characteristics in the pace of learning, in the diversity of interests and in the set of values and information that make them unique and special.

Keywords: Education. ABA. Early Childhood Education.

\section{INTRODUÇÃO}

O presente artigo tem como foco o autismo e a educação com o método ABA (Applied Behavior Analysis). Para refletir sobre o universo autista precisamos argumentar previamente o que é inclusão social, segundo o dicionário Wikipédia refere-se a um conjunto de meios e ações que combatem a exclusão aos benefícios da vida em sociedade. Incluir é a capacidade de compreender reconhecendo o outro com especificidade e limitações.
A inclusão pode ser uma faca de dois gumes. Pode ser algo maravilhoso para o crescimento de todos, mas pode ser motivo de sofrimento de muitos se não estiver bem estruturada. (MINETO, 2008, p.98).

O transtorno do espectro autista (TEA) é uma variedade de transtorno mental do tipo neuro desenvolvimento caracterizado por anormalidade generalizada de interação social e muito restrita e comportamento altamente repetitivo, com causa incerta, fatores de risco inclui ter pais mais velhos, familiares com autismo e certas condições genéticas.

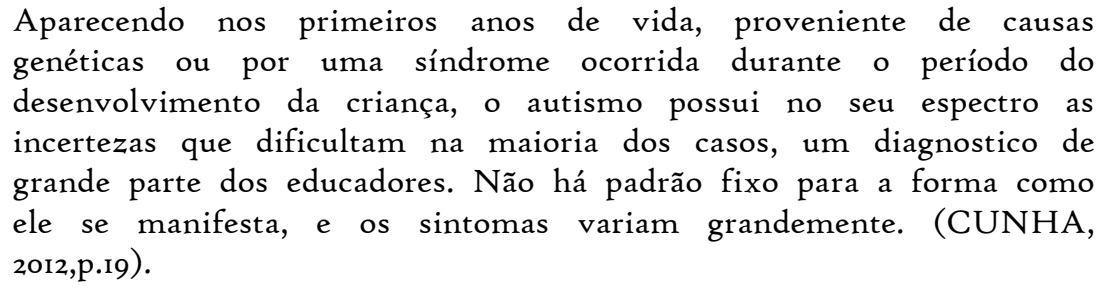
genéticas ou por uma síndrome ocorrida durante o período do desenvolvimento da criança, o autismo possui no seu espectro as incertezas que dificultam na maioria dos casos, um diagnostico de grande parte dos educadores. Não há padrão fixo para a forma como ele se manifesta, e os sintomas variam grandemente. (CUNHA, 2012,p.19).

Por essa peculiaridade, entendemos as dificuldades que os pais, á escola e a todos que o cercam tem de comunicar-se com uma criança autista. Por isso se faz 
necessário uma aproximação adequada e eficiente para que a criança consiga um bom desenvolvimento durante sua vida escolar e social.

A educação mundial na década de 1990 foi marcada por debates relacionados á Educação para Todos e o discurso da Educação Inclusiva na qual destacamos os adventos como a Conferência Mundial sobre Educação para Todos, em Jomtien, Tailândia (UNESCO, 1990) e assinatura de documentos internacionais como a Declaração de Salamanca na Espanha (1994) que discutiu a proposta de inclusão educacional como forma de amenizar a discriminação.

Os documentos orientam o acolhimento a todas as pessoas, independentemente de suas condições físicas, intelectuais, sociais, emocionais ou linguísticos (UNESCO, 1994). No Brasil, a Constituição Federal (BRASIL, 1998) já referendava o mote “Educação para Todos” que, no entanto, nem as rápidas mudanças sociais e as orientações legais têm sido suficientes para garantir o acesso e a permanência com qualidade no processo de escolarização para cada um, indistintamente.

Com a efetivação da Política Nacional de Educação Especial na perspectiva da Educação Inclusiva, em 2008, e o Decreto 6571/2008, propõe-se uma mudança na forma de compreender e efetivar o Atendimento Educacional Especializado (AEE), que deixar de existir como ações em instituições isoladas, substitutivas ao ensino regular, e tornando-se práticas com caráter complementar e suplementar ao Ensino Regular (BRASIL, 2008 ${ }^{\mathrm{a}}$, 2008b), colaborando com melhor eficácia para o exercício da lei.

Com passar dos anos observa-se o aumento dos assuntos relacionados ao TEA, e alguns métodos que são utilizados para melhoria das crianças. Felizmente, a partir dessa nova visão a respeito da deficiência e das pessoas com suas peculiaridades física, mental ou social, ainda longe de ser uma sociedade inclusiva, igualitária e justa a todas as pessoas diversas políticas públicas são implementadas em busca de uma sociedade que permita oportunidade e igualdade a todas as pessoas, independentemente de suas limitações.

Quais as principais contribuições para o desenvolvimento cognitivo do aluno autista podem ser observadas com a intervenção através da análise do comportamento aplicada ABA? A análise do comportamento aplicado teve uma grande proporção na 
clínica como Terapia AB (ABA therapy), é considerada uma abordagem da psicologia que também pode ser usada em pacientes autistas. A ABA tem origem do campo de Behaviorismo, nos estudos Skinner, e é conhecida como uma ciência que "observa, analisa e explica a associação entre o ambiente, o comportamento humano e a aprendizagem" (LEAR, 2004, p.4).

Portanto, logo se tem um determinado comportamento de um aluno autista e realizada a análise sobre ele, podendo ser prensando em uma intervenção para alterar aquele comportamento.

Diante deste contexto este artigo tem como objetivo geral de identificar as principais contribuições para o desenvolvimento cognitivo do aluno autista a partir da intervenção feita através da análise do comportamento aplicadaABA. Assim, os objetivos específicos para alcançar o principal foram pontuados em: Descrever o método ABA; Definir autismo e suas variações; Verificar o desenvolvimento da autonomia intelectual.

Assim, justifica-se que as técnicas de modificação comportamental têm se mostrado bastante eficazes no tratamento, principalmente em casos mais graves de autismo. Para o analista de o comportamento ser terapeuta significa atuar como educador, uma vez que o tratamento envolve um processo abrangente e estruturado de ensino-aprendizagem ou reaprendizagem.

Por tanto, encontrará no desenvolver da leitura deste artigo em sua fundamentação teórica sobre o tema abordado terá três seções. A primeira seção intitulada em UMA BREVE HISTÓRIA SOBRE CIÊNCIA ABA, onde aborda sobre como surgiu a ciência ABA.

A segunda seção abordará sobre A INTERVENÇÃO PRECOCE PODE REDUZIR SINTOMAS, que retrata sobre a utilização do método ser aplicado antecipadamente, assim reduzindo os sintomas do autismo.

E por fim, a terceira seção intitulada em UMA BREVE HISTÓRIA SOBRE AUTISMO, como o próprio tema diz, resumindo a história de como foi a primeira definição deste caso. 


\section{FUNDAMENTAÇÃO TEÓRICA \\ I.I. UMA BREVE HISTÓRIA SOBRE AUTISMO}

O Autismo Infantil foi definido por Kanner(I), em 1943, sendo inicialmente denominado Distúrbio Autístico do Contato Afetivo, como uma condição com características comportamentais bastante específicas, tais como: perturbações das relações afetivas com o meio, solidão autística extrema, inabilidade no uso da linguagem para comunicação, presença de boas potencialidades cognitivas, aspecto físico aparentemente, normal, comportamentos ritualísticos, início precoce e incidência predominante no sexo masculino.

Em 1944, Asperger propôs em seu estudo a definição de um distúrbio que ele denominou Psicopatia Autística, manifestada por transtorno severo na interação social, uso pedante da fala, desajeitamento motor e incidência apenas no sexo masculino. $\mathrm{O}$ autor utilizou a descrição de alguns casos clínicos, caracterizando a história familiar, aspectos físicos e comportamentais, desempenho nos testes de inteligência, além de enfatizar a preocupação com a abordagem educacional destes indivíduos.

Na décima revisão da Classificação Internacional de Doenças - CID ıo(33), os Transtornos Globais do Desenvolvimento foram classificados como um grupo de alterações, caracterizadas por alterações qualitativas da interação social e modalidades de comunicação, e por um repertório de interesses e atividades restrito e estereotipado. Essas anomalias qualitativas constituem uma característica global do funcionamento do indivíduo.

\subsection{UMA BREVE HISTÓRIA SOBRE CIÊNCIA ABA}

ABA é a abreviação para Applied Behavior Analysis. É conhecida também como Análise do Comportamento Aplicada. Muitos definem a aplicação de ABA para crianças autistas como "aprendizagem sem erro".

A terapia ABA envolve o ensino intensivo $e$ individualizado das habilidades necessárias para que a criança autista possa adquirir independência e a melhor qualidade de vida possível. Dentre as habilidades ensinadas incluem-se os 
comportamentos interferem no desenvolvimento e integração do indivíduo diagnosticado com autismo.

De acordo com o Manual Autism Speaks (20II), a Análise do Comportamento é a ciência que fornece conhecimentos cientificamente comprovados sobre como e porque o comportamento ocorre.

Segundo o Manual "quando esta pesquisa é utilizada para melhorar o comportamento socialmente significativo, considera-se que é aplicada" (p. 34). Camargo e Rispoli (2013) abordam que a ABA também pode ser "definida como uma tecnologia que é aplicada em situações de vida reais, onde comportamentos apropriados e inapropriados podem ser melhorados, aumentados ou diminuídos" (RISPOLI, 2013, p.642).

Conforme Haydu (2009), o comportamento pode ser definido como um processo de interação entre o indivíduo e o ambiente, sendo que os indivíduos e os eventos ambientais interagem e assim, afetam um ao outro, produzindo alterações em ambos.

Para identificar se o método esta sendo positivo para o aluno, é necessários observações e exames constantes. O profissional responsável deve elaborar registros rigorosos e detalhados, a partir disso coletar dados e identificar se esta acontecendo há evolução das habilidades desejadas. Contudo, o método ABA deve ser aplicada por profissionais na área de analise comportamental com experiência supervisionada e pratica no método para alunos com autismo.

As experimentações originais da terapia comportamental trouxeram algumas vantagens importantes ao clínico: ele foi treinado na observação de comportamentos verbais e não verbais, tanto em casa, como na escola ou no consultório, o que é fonte de dados relevantes. Ele estuda o papel que o ambiente desempenha - ambiente este onde é possível interferir e verificar as hipóteses levantadas.

Outra habilidade é o entendimento do que é observado como um processo comportamental, com contínuas interações e, portanto, sujeito a mudanças (Windholz, 2002). Segundo Windholz (1995), existe uma relação direta terapeuta e educador, pois, para o analista do comportamento ser terapeuta significa atuar como educador, uma vez que o tratamento envolve um processo abrangente 
e estruturado de ensino-aprendizagem ou reaprendizagem. Para Meyer (2003), um dos princípios básicos da metodologia $\mathrm{ABA}$ é que um comportamento é determinado por qualquer ação que pode ser observada e contada, tendo sempre uma frequência e uma duração.

Segundo ele, este comportamento pode ser explicado pela identificação do que antecedeu e das possíveis consequências deste. Ou seja, é a identificação das relações entre os eventos ambientais e as ações do organismo. Nesse contexto, estes comportamentos são motivados, de forma prazerosa. Tendo uma função exclusiva, ou seja, a de servir para conseguir algo que se deseja. É sabido, que todo comportamento de um modo geral é aprendido, seja ele, "bom" ou "mal". Isso não significa que alguém intencionalmente nos ensinou a exibir um determinado tipo de comportamento ruim, mas, aprendemos que eles são eficazes para conseguirmos o que queremos.

Dentro dessa perspectiva, entendemos que o método ABA pode intencionalmente ensinar a criança a exibir comportamentos mais adequados no lugar dos comportamentos ruins, ou ditos, problemas. Comportamentos estão relacionados a eventos ou estímulos que os precedem, que são os antecedentes e a sua probabilidade de ocorrência futura está relacionada às consequências que os seguem.

O Behaviorismo concentra-se na análise objetiva do comportamento observável e mensurável em oposição, por exemplo, à abordagem psicanalítica, que assume que muito do nosso comportamento deve-se a processos inconscientes. Ivan Pavlov, John B. Watson, Edward Thorndike e B.F. Skinner foram os pioneiros que pesquisa e descobriram os princípios científicos do Behaviorismo.

Por esta razão, e frente a essa quebra de paradigmas na mudança de comportamentos, na metodologia $\mathrm{ABA}$, os objetivos da intervenção são representados em ordem abaixo:

- Trabalhar os déficits, identificando os comportamentos que a criança tem dificuldades ou até inabilidades e que prejudicam sua vida e suas aprendizagens; 
- Diminuir a freqüência e intensidade de comportamentos de birra ou indesejáveis, como por exemplo: agressividade, estereotipias e outros que dificultam o convívio social e aprendizagem deste individuam;

- Promover o desenvolvimento de habilidades sociais, comunicativa, adaptativas, cognitivas, acadêmicas etc;

- $\quad$ Promover comportamentos socialmente desejáveis;

Segundo Moreira e Medeiros (2007), essa intervenção, representada na figura 2, é baseada em uma análise funcional, ou seja, analisa a função do comportamento determinante, visando eliminar os comportamentos socialmente indesejáveis.

Este por sua vez, é um ponto central para entendermos qual é o propósito do comportamento "problema" que a criança está apresentando e, através disso, montarmos a intervenção para modificá-lo.

Se o comportamento é influenciado por suas consequências, podemos manipulá-las para entendermos melhor como essa consequência se dá e também modificar os comportamentos das pessoas, programando consequências especiais para tal. Daí, entendemos que para se resolver um comportamento "problema", o primeiro passo é identificar a sua função.

Se não soubermos por que uma criança deve se engajar em um comportamento adequado (qual a função ou propósito), será difícil saber como devemos ensiná-las. Pais, terapeutas e educadores tendem a imaginar ou achar um motivo para o comportamento e isso incorrerá no insucesso da intervenção.

A avaliação comportamental é a fase da descoberta, e visa à identificação e o entendimento de alguns aspectos relativos à criança com autismo e seu ambiente. Alguns dos objetivos da avaliação são: a baixa pontuamos quais representa os objetivos da avaliação do método $\mathrm{ABA}$ uma vez identificada as possibilidades de intervenção, pontuados as fragilidades e pontos de atenção da avaliação, conseguimos, com base nesses dados, partir para o planejamento associado a metodologia $\mathrm{ABA}$, que seria traçar pequenos objetivos em curto prazo alguns exemplos: 
- Entender o repertório de comunicação da criança: presença ou não de linguagem funcional, contato visual, atendimento de ordens, entre outros;

- Como ela se relaciona em seu ambiente: brinquedos preferidos apresentam birras frequentes, como reage às pessoas;

- Qual a função de seus comportamentos;

- Em que circunstâncias certos problemas ocorrem ou deixam de ocorrer com maior freqüência ou intensidade?

- Quais as conseqüências fornecidas a esses comportamentos problema?

Modificando os antecedentes podemos prevenir que o comportamento problema aconteça. Isto é realizado de diferentes maneiras:

I. Evitando situações ou pessoas que sirvam como antecedentes para o comportamento problema

2. Controlando o meio ambiente - no decorrer da vida do indivíduo o ambiente modela, cria um repertório comportamental e o mantém; o ambiente ainda estabelece as ocasiões nas quais o comportamento acontece, já que este não ocorre no vácuo (Windholz, 2002).

3. Dividindo as tarefas em passos menores e mais toleráveis, o que chamamos de aprendizagem sem erro. Toda a intervenção está baseada na aprendizagem sem erros, ou seja, deixamos de lado o histórico de fracassos e ensinamos a criança a aprender.

Esta aprendizagem deve ser prazerosa e divertida para a criança, podendo-se usar reforçadores para manter a criança motivada. Um reforço é uma conseqüência que aumenta a probabilidade de esta resposta acontecer novamente. Quando um comportamento é fortalecido, é mais provável que ele ocorra no futuro.

No Art. Io É instituída a Lei Brasileira de Inclusão da Pessoa com Deficiência (Estatuto da Pessoa com Deficiência), destinada a assegurar e a promover, em condições de igualdade, o exercício dos direitos e das liberdades fundamentais por pessoa com deficiência, visando à sua inclusão social e cidadania.

Parágrafo único. Esta Lei tem como base a Convenção sobre os Direitos das 
Pessoas com Deficiência e seu Protocolo Facultativo, ratificados pelo Congresso Nacional por meio do Decreto Legislativo $\mathrm{n}^{\mathrm{o}} \mathrm{186}$, de 9 de julho de 2008, em conformidade com 0 procedimento previsto no $\S 3^{\circ}$ do art. $5^{\circ}$ da Constituição da República Federativa do Brasil, em vigor para o Brasil, no plano jurídico externo, desde 3I de agosto de 2008, e promulgados pelo Decreto $\mathrm{n}^{\circ}$ 6.949, de 25 de agosto de 2009, data de início de sua vigência no plano interno.

A Declaração de Salamanca é considerada um dos principais documentos mundiais que visam a inclusão social, ao lado da Convenção de Direitos da Criança (1988) e da Declaração sobre Educação para Todos de I99o.

Uma das implicações educacionais orientadas a partir da Declaração de Salamanca refere-se à inclusão na educação. Segundo o documento, "o princípio fundamental da escola inclusiva é o de que todas as crianças deveriam aprender juntas, independentemente de quaisquer dificuldades ou diferenças que possam ter”.

Do Direito À Educação E Do Dever De Educar Art. 4º. O dever do Estado com educação escolar pública será efetivado mediante a garantia de:

III - atendimento educacional especializado gratuito aos educandos com necessidades especiais, preferencialmente na rede regular de ensino;

Por tanto, a execução na pratica da lei será de estrema importância para que nossas crianças com autismo tenha uma educação adaptada para o seu grau de comprometimento e garantindo uma educação inclusiva.

\section{r.3. A INTERVENÇÃO PRECOCE PODE REDUZIR SINTOMAS}

A Neuroplasticidade refere-se à capacidade do cérebro de mudar, se adaptar e desenvolver novas conexões sinápticas entre os neurônios. Entretanto, apesar de ser possível a criação de novas conexões neuronais em indivíduos adultos, o cérebro é mais plástico até a idade de cinco anos.

Além de a plasticidade ser maior nos primeiros anos de vida, acontece também nessa época um fenômeno importante chamado "poda neuronal". Tal fenômeno pode ser brevemente descrito como um momento em que o cérebro “descarta" os neurônios que até então não se desenvolveram ou não estavam sendo 
utilizados de maneira adequada.

Uma das primeiras podas neuronais ocorre na primeira infância, coincidindo, muitas vezes, com a época em que os pais relatam regressão e perda de habilidades por parte de seus filhos. Ou seja, os pais podem relacionar a regressão a causas ambientais e ela ter causas neurológicas. De qualquer forma, perdas de habilidades, em qualquer tempo, não podem ser desconsideradas. Mais que lamentar por elas, os pais devem vê-las como um sinal que está ali para mostrá-los que algo não está bem, precisa ser investigado e requer tomada de providências.

Considerando todos esses fatores (podas neuronais e plasticidade cerebral), a época em que as intervenções são iniciadas faz muita diferença: quanto mais cedo, melhor. Hoje não tenho dúvidas de que em algum momento isso aconteceria, pois havia uma predisposição e em algum momento outro episódio iria fazer com que os sintomas se tornassem mais evidente.

\footnotetext{
Para as crianças com autismo, o diagnostico precoce é de fundamental importância. Por isso, os pediatras precisam observálas com muito critério desde o nascimento e, a qualquer alteração notada deve encaminhá-las a um especialista mesmo que não tenham certeza do diagnostico [...]. (GAIATO, 2012, p.137).
}

\section{METODOLOGIA DA PESQUISA}

Para o desenvolvimento deste artigo, caracteriza-se em uma pesquisa de abordagem qualitativa que conforme Minayo (200I, p.2I) "A pesquisa qualitativa responde a questões muito particulares. Ela se preocupa, nas ciências sociais, com um nível de realidade que não pode ser quantificado. Ou seja, ela trabalha com o universo de significados, motivos, aspirações, crenças, valores e atitudes, o que corresponde a um espaço mais profundo das relações, dos processos e dos fenômenos que não podem ser reduzidos à operacionalização de variáveis", tendo como objeto de estudo exploratório onde tem o intuito de explorar a revisão bibliográfica sobre o tem autismo e educação, em busca de descrever o método ABA como proposta de intervenção na educação infantil. 


\section{I. Classificação da pesquisa}

O estudo de pesquisa de forma exploratória tendo como objetivo de investigar através de materiais bibliográficos, analisando detalhadamente através de teóricos e autores que abordam sobre o presente tema.

\subsection{Local da pesquisa}

Para o embasamento para contextualizar e abordar este tema foi composta por artigos científicos e monografias que são relacionadas ao tema de estudo.

\subsection{Sujeito da pesquisa}

Os sujeitos da pesquisa foram através de teóricos que abordam sobre o tema de acordo com as suas perspectivas e análises de estudo.

\subsection{Instrumentos de coleta de dados e procedimentos}

Foram utilizados artigos entre 1996 á 2019, apresentados e publicados em simpósios e congressos científicos obtendo matérias de referência para bases teóricas sobre educação e autismo e o método ABA.

\section{RESULTADOS E DISCUSSÕES}

Através da análise bibliográfica de forma exploratória de investigar teoricamente e descrever sobre o método ABA como proposta de intervenção na educação infantil constatou-se que a educação inclusiva, a escola precisa estar preparada para enfrentar os desafios e necessidades de oferecer uma educação com qualidade para todos os seus alunos. Torna-se fundamental que a educação com qualidade considere que, cada aluno numa escola, demonstra características próprias no ritmo de aprendizagem, na diversidade de interesses e no conjunto de valores e informações que os tornam únicos e especiais.

Segundo (FRIAS;MENEZES.2008) O desafio da escola é proporcionar a diversidade de alunos que nela é representado, tentativas de se construir um conceito que possua bons resultados no processo ensino e aprendizagem, de forma 
que sejam incluídos neste processo todos que dele são por direito.

Desta forma, torna-se necessário a inclusão dos autistas, uma vez que a inclusão traz como premissa básica, proporcionar a educação para todos, pois é um direito constitucional do aluno autista, ou de qualquer outra necessidade educacional especial e de todos os cidadãos à educação.

Partindo da premissa de que todo comportamento pode ser explicado pela identificação da sua causa e de suas consequências, compete ao analista do comportamento de uma criança autista ensinar comportamentos alternativos que possam provocar as mesmas consequências que o comportamento inapropriado provocava, já que tais comportamentos interferem no desenvolvimento e na interação dessa criança.

Para isso, deve identificar as habilidades apresentadas pela criança e as que ela precisa aprender, o que envolve um ensino intensivo e individualizado para novas habilidades (BRAGAKENYON, KENYON; MIGUEL, 2005).

Atentar para as dificuldades e facilidades da criança em aprender.
Tudo deve ser planejado de acordo com estilo de aprendizagem de
cada criança, demonstrado pelos dados. Os dados são registros de
como a criança está respondendo a cada programa; Por exemplo
se ela acertou ou errou perguntas, se precisou de ajuda [...]. Esse
Numero em geral se transformam em gráficos que serão usados
para pelo analista do comportamento para tomar decisões
continuamente em relação ao sucesso de sua intervenção
(FAZZIO,2012,p.15).

Considerando os tópicos acima, denotados aqui como dificuldades e/ou desafios de aprendizagem, percebemos como pode ser difícil para uma criança com autismo prestar atenção $e$ aprender da maneira que uma criança com desenvolvimento típico faz. Dentro desse contexto, abordaremos sobre a metodologia $\mathrm{ABA}$, a qual vem sendo usada como um método de intervenção eficaz do comportamento da pessoa com autismo, que dentre tantos benefícios, corrobora para ganhos no desenvolvimento cognitivo e pedagógico dessas crianças.

Por esse viés destacamos as pessoas com deficiência que representam cerca de I0\% a $15 \%$ da população brasileira que historicamente estão distante da convivência social com seus pares isso porque, culturalmente, a sociedade criou uma (pseudo) 
imagem de normalidade de forma que as pessoas que não se harmonizam ao padrão estabelecido eram segregadas a partir de suas diferenças, ou seja, encontravam-se privados da convivência social, pois o paradigma vigente estigmatizava o déficit e impedia de enxergar a pessoa humana integralmente, tanto suas limitações como o seu potencial.

A Análise do Comportamento Aplicada (Applied Behavior Analysis) é um termo advindo do campo científico do Behaviorismo, que observa, analisa e explica a associação entre o ambiente, o comportamento humano e a aprendizagem. Uma vez que um comportamento é analisado, um plano de ação pode ser exercido para modificar aquele comportamento.

A análise do comportamento aplicada, ou ABA é uma abordagem da psicologia que é usada para a compreensão do comportamento e vem sendo amplamente utilizada no atendimento a pessoas com desenvolvimento atípico, como os transtornos invasivos do desenvolvimento (TIDs). (Lear, K., 2004) De acordo com Anderson (2007), a metodologia ABA.

É o uso cientifico dos princípios da abordagem comportamental
para desenvolver, manter e aumentar comportamentos desejados e
diminuir comportamentos indesejados. Envolvendo uma serie de
diferentes estratégias, que podem ser utilizadas em variadas
situações para podificar ou ensinar
comportamentos (ANDERSON, 2007, p.ro).

\section{CONSIDERAÇÕES FINAIS}

Durante o desenvolvimento do presente artigo compreendi a importância de descrever sobre a inclusão no contexto escolar, pois é fundamental que durante a formação acadêmica em licenciatura onde se trabalha com a educação, se faz necessário conhecermos tudo sobre a evolução e diferenças humanas, podendo assim acompanhar o desenvolvimento socio educacional.

$\mathrm{Na}$ construção deste trabalho constatei, através de teóricos e autores que abordam sobre o presente tema de que, o método ABA é um modelo eficaz para ser trabalhado com crianças portadoras do autismo, pois os ajuda a desenvolver positivamente na cognição. Entendemos também que o método $A B A$ pode intencionalmente ensinar a criança a exibir comportamentos mais adequados no 
lugar dos comportamentos ruins, ou ditos, problemas. Comportamentos estão relacionados a eventos ou estímulos que os precedem, que são os antecedentes e a sua probabilidade de ocorrência futura está relacionada às consequências que os seguem.

Os resultados encontrados através de estudo bibliográfico de forma exploratória, buscando entender mais sobre a eficácia deste método, percebemos como pode ser difícil para uma criança com autismo prestar atenção e aprender da maneira que uma criança com desenvolvimento típico faz. Dentro desse contexto, abordaremos sobre a metodologia ABA, a qual vem sendo usada como um método de intervenção eficaz do comportamento da pessoa com autismo, que dentre tantos benefícios, corrobora para ganhos no desenvolvimento cognitivo e pedagógico dessas crianças.

Com tudo, verifiquei a suma imortância da aplicação do método ABA na Educção Infantil pois trazem benefícios pois trabalha no esforço comportamental positivas, diminuindo as frustações, garantindo os alunos um aprendizado sem erros podendo ajudar na motivação e no prazer de aprender.

\section{REFERÊNCIAS}

BRASIL/MEC. Lei $\mathbf{n}^{\circ}$.9.394, de 20 de dezembro de 1996. Lei de Diretrizes $r$ Bases da Educação Nacional. Brasília, DF: 20 de dezembro de 1996.

CUNHA, Eugênio. Autismo e inclusão: psicopedagogia e práticas educativas na escola e na família. 4 ed.Rio de Janeiro: Wak Editora,2012. Acesso em: 24 de outubro.

\section{FARIAS, E. M. A., MENEZES, M. C. B. Inclusão Escolar do Aluno com} Necessidades Educacionais Especiais: contribuições ao professor do Ensino Regular. Disponível em: http://www.diaadiaeducacao.pr.gov.br/portals/pde/arquivos/I4628.pdf G. Acesso em: 22 de outubro.

FAZZIO, D. O Verdadeiro ABA: Um Programa Público Modelo de Intervenção Comportamental Precoce Para Crianças Com Autismo. Revista Autismo. N. 2. Abril, 2012. Disponível em: Acesso em: 07 de novembro.

GAIATO, Mayara Bonifácio; REVELES Leandro Thadeu; SILVA, Ana Beatriz Barbosa. Mundo Singular: Entenda o autismo. FONTANAR, São Paulo- SP, 2012. Acesso em: 29 de outubro. 
Lei Brasileira da Inclusão da Pessoa com Deficiência (Estatuto da Pessoa com Deficiência). Lei ${ }^{\circ}$ 13,146, de 6 de julho de 2015. Acesso em: or de outubro.

MINAYO, Maria Cecília de Souza (org.). Pesquisa Social. Teoria, método e criatividade. 18 ed. Petrópolis: Vozes, 200I.

MINETTO, Maria de Fátima. Currículo na Educação Inclusiva: entendendo esse desafio/Maria de Fátima Minetto. 2. Ed. Curitiba: ibpex, 2008. Acesso em: 18 de outubro.

UCHÔA, YASMIM FIGUEREDO. A criança autista na educação infantil (Trabalho de conclusão de curso). PB- Campina Grande, 2015. Disponível em: http://dspace.bc.uepb.edu.br//jspui/bitstream/123456789/7959/I/PDF\%20\%20 Yasmim\%2oFigueiredo\%2oUchôa.pdf. Acesso em: 04 de outubro. 